\title{
Adjunctive Low-level Laser Therapy Using 980-nm Diode Laser after Impacted Mandibular Third Molar Surgery: A Randomized Clinical Trial
}

\author{
Sirous Risbaf Fakour ${ }^{1}$, Hadi Hashemzehi², Hassan Jahantigh ${ }^{3}$, Kimia Arab $^{4}$, Leila \\ Gholami ${ }^{5 * *}$ \\ ${ }^{I}$ Associate Professor, Department of Oral and Maxillofacial Surgery, School of Dentistry, Zahedan University of Medical \\ Sciences, Zahedan, Iran \\ ${ }^{2}$ Assistant Professor, Department of Oral and Maxillofacial Surgery, School of Dentistry, Hamadan University of Medical \\ Sciences, Hamadan, Iran \\ ${ }^{3}$ Dentist, Department of Prosthodontics, School of Dentistry, Zahedan University of Medical Sciences, Zahedan, Iran \\ ${ }^{4}$ Dentist, School of Dentistry, Zahedan University of Medical Sciences, Zahedan, Iran \\ ${ }^{5}$ Assistant Professor, Dental Implant Research Center, Department of Periodontology, School of Dentistry, Hamadan \\ University of Medical Sciences, Hamadan, Iran \\ * Corresponding Author: Leila Gholami, Dental Implant Research Center, Department of Periodontology, School of \\ Dentistry, Hamadan University of Medical Sciences, Hamadan, Iran. Email: l.gholami@hotmail.com
}

Received: 15.10 .2019

Accepted: 22.01 .2020

How to Cite this Article: Risbaf Fakour S, Hashemzehi H, Jahantigh H, Arab K, Gholami L. Adjunctive Low-level Laser Therapy Using 980-nm Diode Laser after Impacted Mandibular Third Molar Surgery: A Randomized Clinical Trial. Avicenna J Clin Med. 2020; 26(4): 199-205. DOI: $10.29252 /$ ajcm.26.4.199

\section{Abstract}

Background and Objective: Extraction of impacted lower third molars is one of the most frequent surgeries of the oral cavity. This operation might be accompanied by inevitable complications, such as pain, swelling, and trismus after surgery. Therefore, the aim of this study was to evaluate the impact of low-intensity/power laser therapy on swelling and trismus after impacted mandibular third molar surgery.

Materials and Methods: This randomized double-blind clinical trial was performed on 40 patients who required similar unilateral impacted third molars. These patients were randomly divided into two groups of 20 , including the control group with no laser application and the test group receiving laser irradiation. In the intervention group $1 \mathrm{~cm}^{2}$ of the tissue was irradiated immediately post-operation by $12 \mathrm{j} / \mathrm{cm}^{2}$ energy using a $980-\mathrm{nm}$ laser setting with continuous wave mode at the output power of $200 \mathrm{MW}$ for $60 \mathrm{~s}$. Radiations were carried out at three regions, including two intraoral sites on the buccal and lingual sides of the operated area and an extraoral area on the joining point of the masseter muscle to the mandible. Inflammation and trismus were assessed by measuring the size of the face and maximum mouth opening on the second and seventh days after surgery. Results: Our findings demonstrated that in the laser group, on the second day post-operation the maximum mouth opening (trismus) was $28 \pm 6$ and facial swelling was $217.8 \pm 12.8$. The two groups were not significantly different on this day regarding the two evaluated variables $(\mathrm{P}>0.05)$. On the seventh day, trismus and facial swelling were reported as $39.85 \pm 6.97$ and $209.2 \pm 13.45$, respectively. Moreover, improvements were observed in the irradiated group at this time point. However, no statistically significant difference was found between the test and control group concerning these factors $(\mathrm{P}>0.05)$.

Conclusion: According to the results of this study, laser application with the parameters set in this study had no significant positive effects on reducing the post-operation complications.

Keywords: Laser Therapy, Oral Surgery, Third Molar 


\section{درمان مكمل ليزر كمتوان با ديود • ه1 نانومتر يس از جراحى دندان مولرسوم نهفته: يك كار آزمايى بالينى تصادفى}

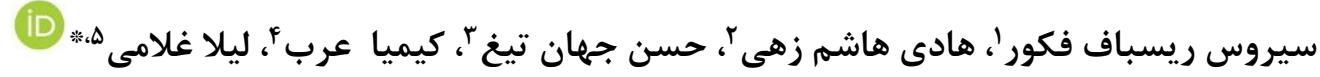

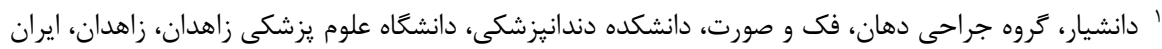

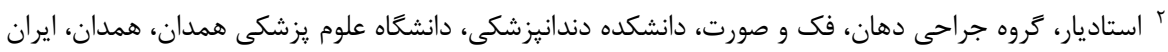

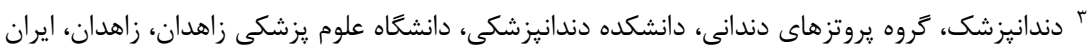

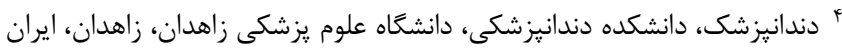

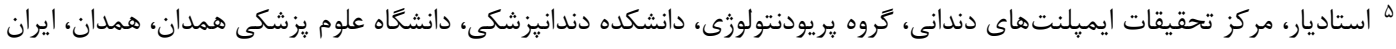
* نويسنده مسئول: ليلا غلامى، مركز تحقيقات ايميلنتهاى دندانى، گروه بريودنتولوزى، دانشكده دندانيزشكى، دانشعاه علوم بزشكى همدان، همدان، ايران. ايميل: 1.gholami@hotmail.com

$$
\text { جكيده }
$$

سابقه و هدف: جراحى دندانهاى عقل نهفته يكى از شايعترين جراحىهاى حفره دهان است كه مىتواند

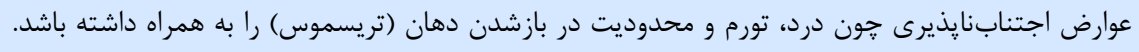

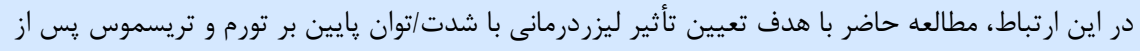
جراحى مولرسوم نهفته فك يايين انجام شد.

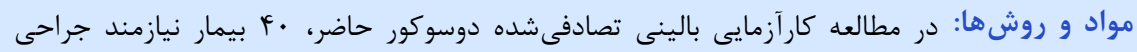

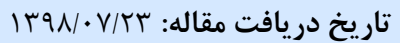

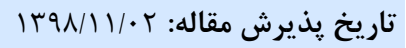
تمامى حقوق نشر براى دانشگاه علوم يزشكى همدان محفوظ است.

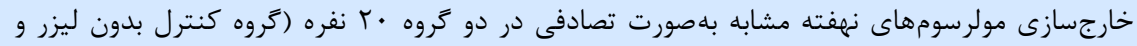

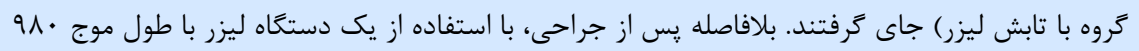

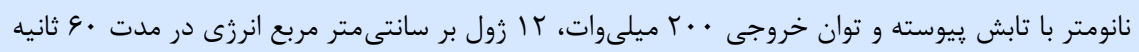

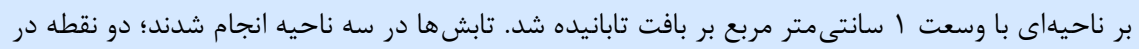

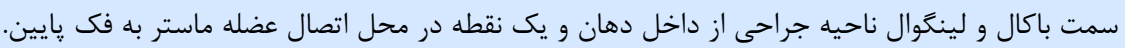

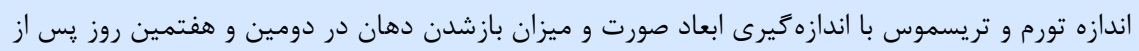
جراحى بررسى ترديد.

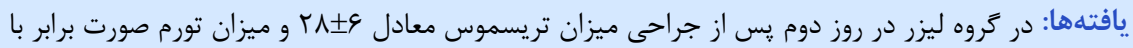

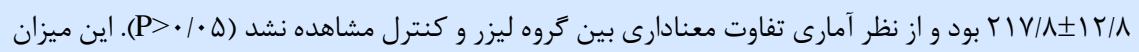

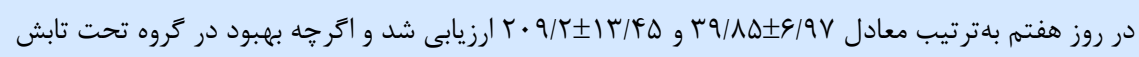

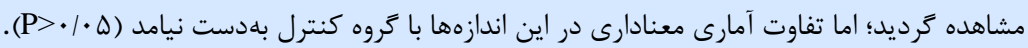

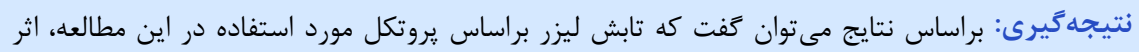

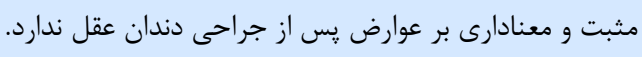
وازگًان كليدى: جراحى دهان، دندان عقل، ليزردرمانى

مى يابد. تريسموس به دليل گرفتگى در عضلات جونده ايجاد شده

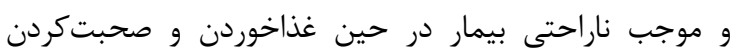

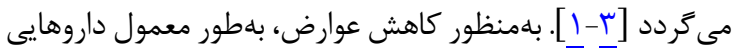
جون كورتيكواستروئيدها و Nonsteroidal Anti-) NSAIDS تجويز مىشوند؛ اما اين داروها مى توانند عوارض جانبى مختلفى مانند زخم معده، واكنشهاى
يكى از رايجترين جراحىهاى حفره دهان، جراحى

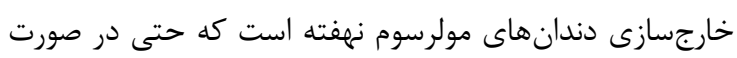

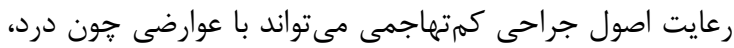
تورم، تريسموس و يا محدوديت در بازكردن دهان همردي همراه

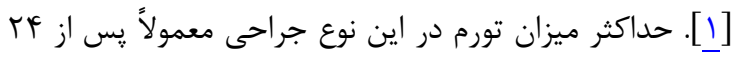

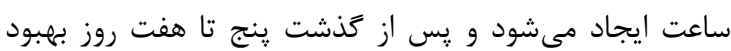


سيستميك كامل كه داراى نهفتگى دندان مولرسوم مشابه بهصورت مزيو انكولار كلاس II و I و A I بودند، مورد مطالعه قرار گرفتند. وجود بيمارى سيستميك، عفونت موضعى (همجون

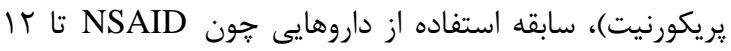

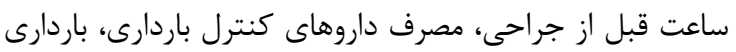

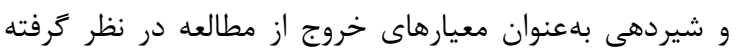

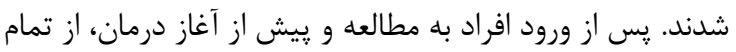

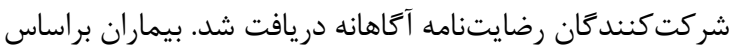

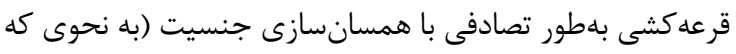

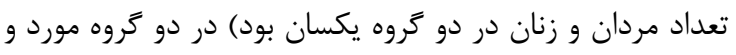

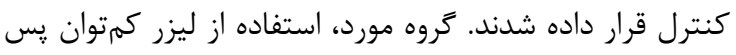
از جراحى و كروه كنترل، بدون تابش ليزر بود.

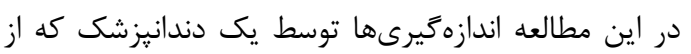

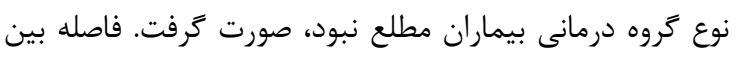

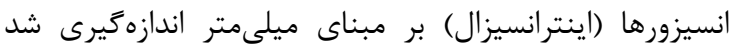

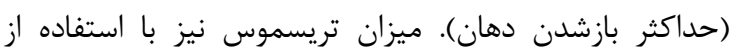

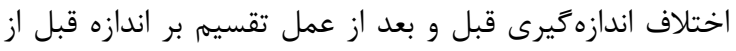
عمل بلصورت درصد محاسبه ترديد.

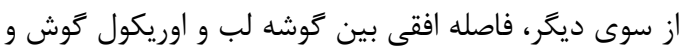

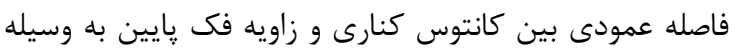

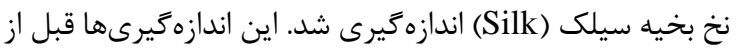

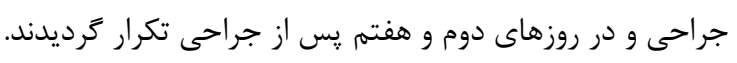

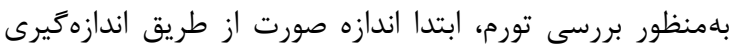

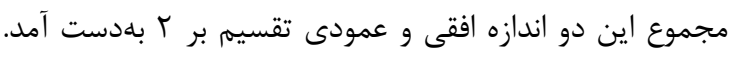

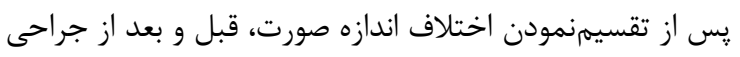

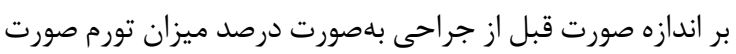
محاسبه كرديد. بلهنظور جراحى دندان عقل نهفته از حداكثر r كاريول

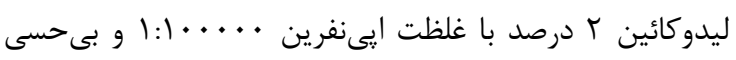

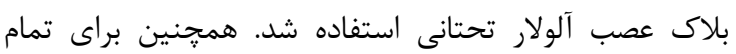

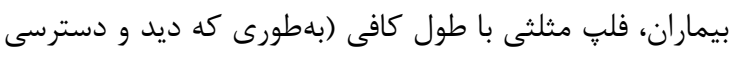

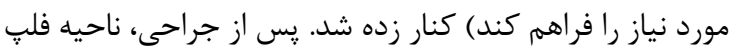

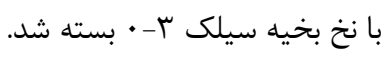

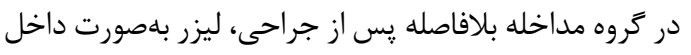

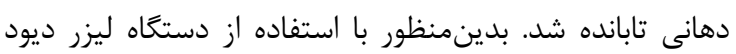
Doctor Smile WISER/LA3D0 001.3)

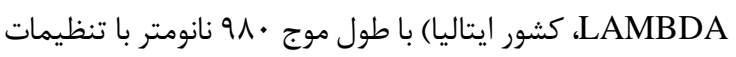

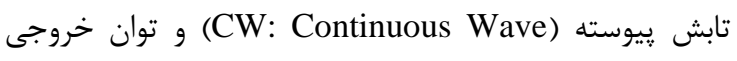

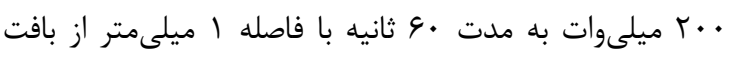
توسط سرقلم Flat top therapy در ناحيهاى با سطح مقطع 1 سانتىمتر مربع تابش صورت زرفت كه مطابق با مطالعات

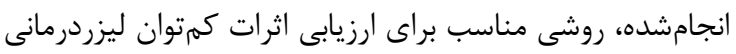

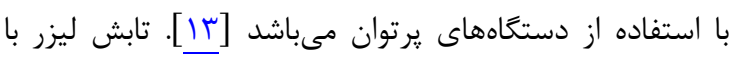
دانسيته انرزى rا زول بر سانتىمتر مربع در سه ناحيه انجام شد؛
آلرزيك، افزايش فشار خون، نارسايى قلبى، آترواسكلروز و تداخل

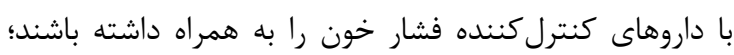

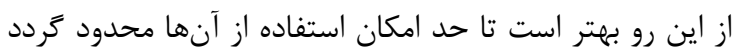

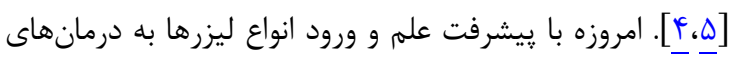

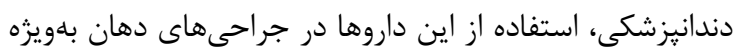

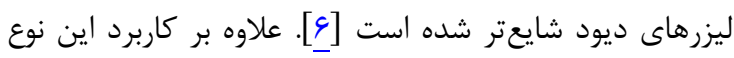

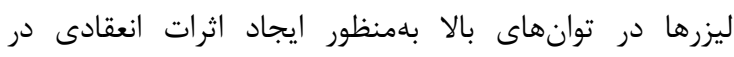

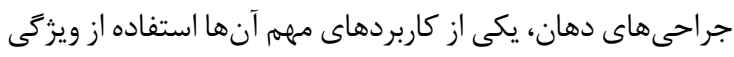

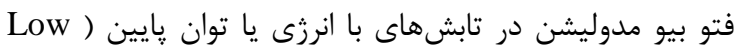
فئو بيو مدوليشن در تابشهاى LLevel/Intensity Laser Therapy LLLT/ LILT كه در زمينههاى مختلف درمانهاى يزشكى همجون صدمات اسكلتى - عضلانى و بيمارى هاى تخريب كنينده مورد استفاده قرار

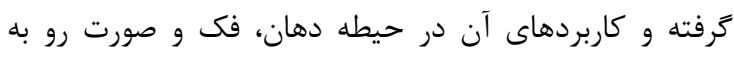

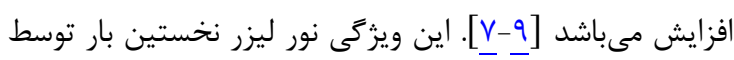

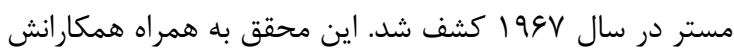
اثرات نور ليزر را بر بافتهاى مختلف مورد مطالعه قرار دادند.

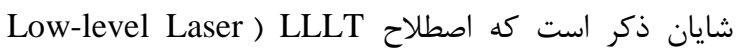
(Therapy نزديك به مادون قرمز براى كنترل درد و ترميهم بافتى اطلاق

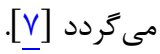
علاوهبراين، از ليزرهاى كمتودان در دردان داندانيزشكى براى

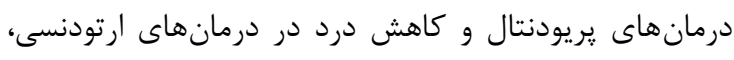

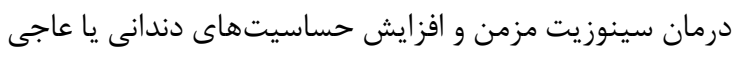

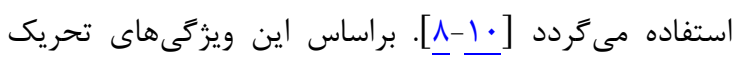

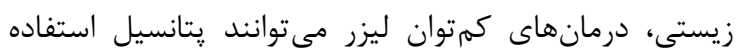

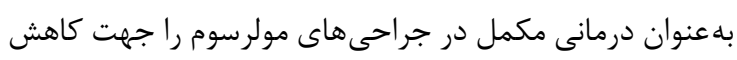

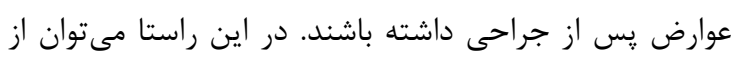

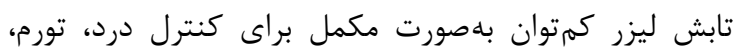

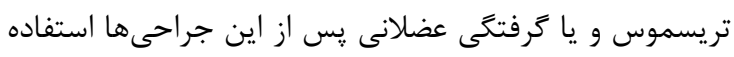
نمود [11، [11)] آرجه استفاده از درمان ليزر كمتوان موضوع مطالعات

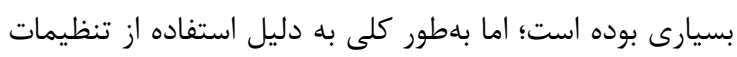

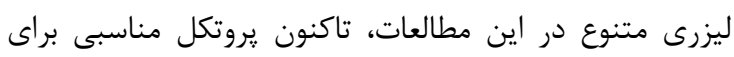

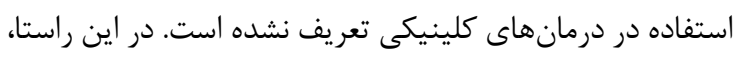

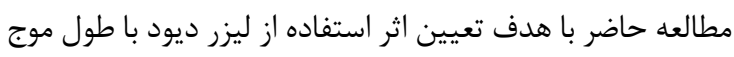

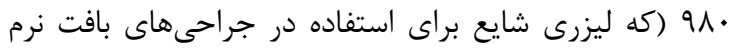

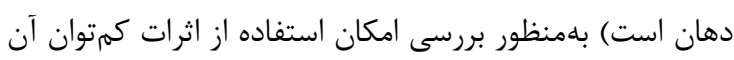

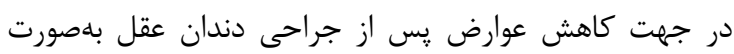

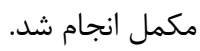

\section{مواد و روشها}

در كارآزمايى بالينى تصادفىسازىشده دوسوكور حاضر براى

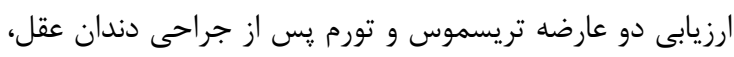

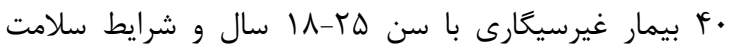




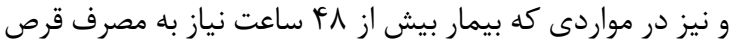

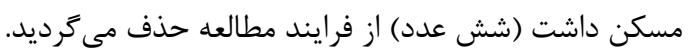

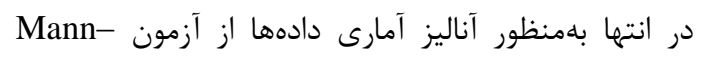
Whitney

$$
\text { كمتر از ه•• (• در نظر كرفته شد. }
$$

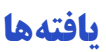

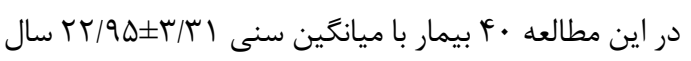

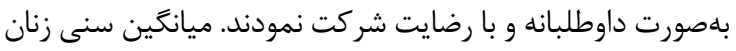

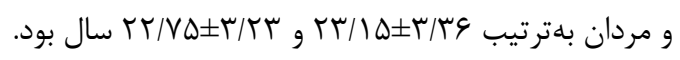

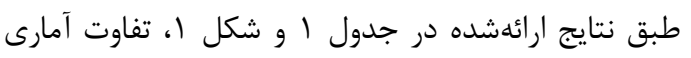

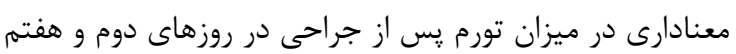

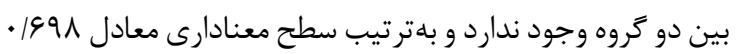

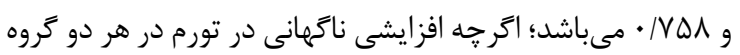

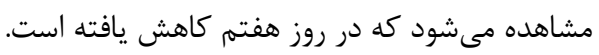

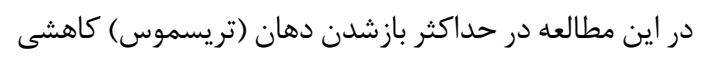

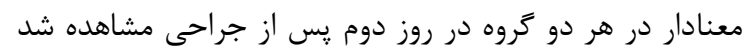

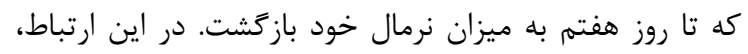

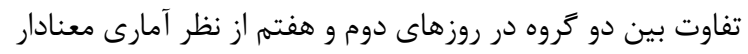

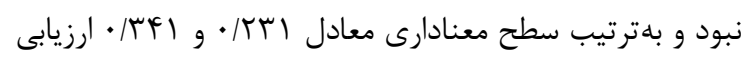

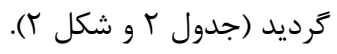

يك نقطه در سمت باكال، يك نقطه در سمت لينكَوال روى ناحيه

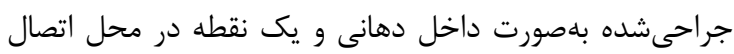

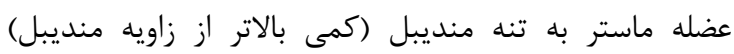

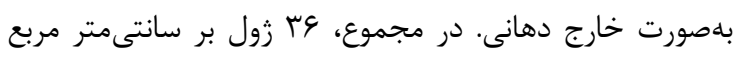

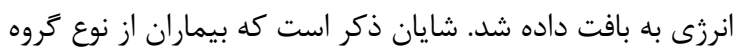

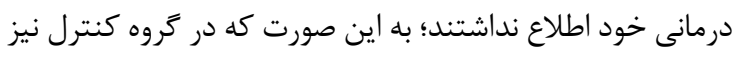
از ليزر خاموش جهت شبيهسازى در همان نواحى استفاده كرديد.

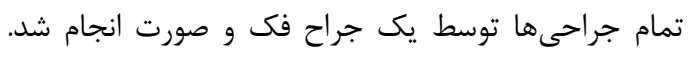

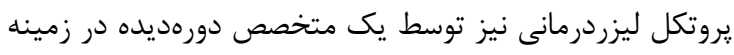

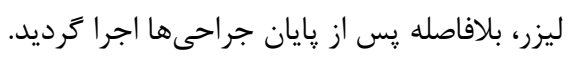

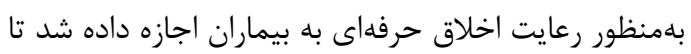

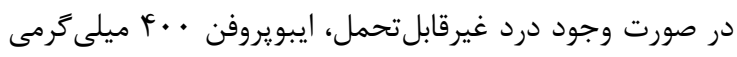

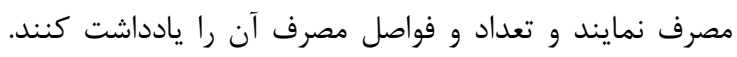

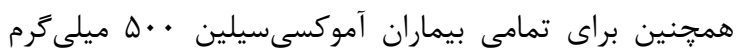

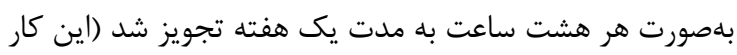

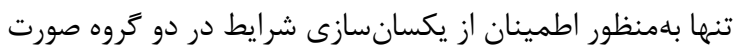

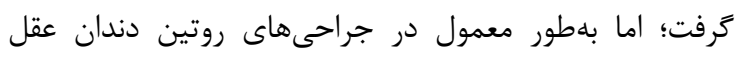

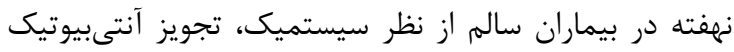

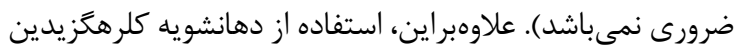

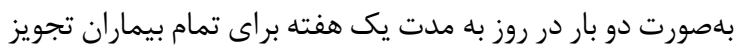

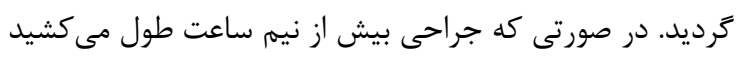

\section{جدول ا: ميانگين تورم در زمان هاى مختلف در گروههاى مورد مطالعه}

\begin{tabular}{|c|c|c|c|}
\hline سطح معنادارى & ميانكين土|نحراف معيار & 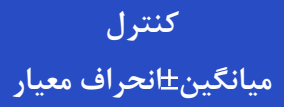 & 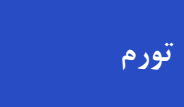 \\
\hline$\cdot 19 \cdot r$ & $r \cdot \Lambda / G \pm|r /| F$ & $r \cdot V / 9 \pm 1 \cdot / 94$ & قبل از جراحى \\
\hline$\cdot 1991$ & $r / V / \Lambda \pm I r / \Lambda$ & $r / 9 / r \pm q / 9$ & روز دوم \\
\hline$\cdot / V \Delta \Lambda$ & $r \cdot q / r \pm 1 r / 4 \Delta$ & $r \cdot q / T \pm 1$. & روز هفتم \\
\hline
\end{tabular}

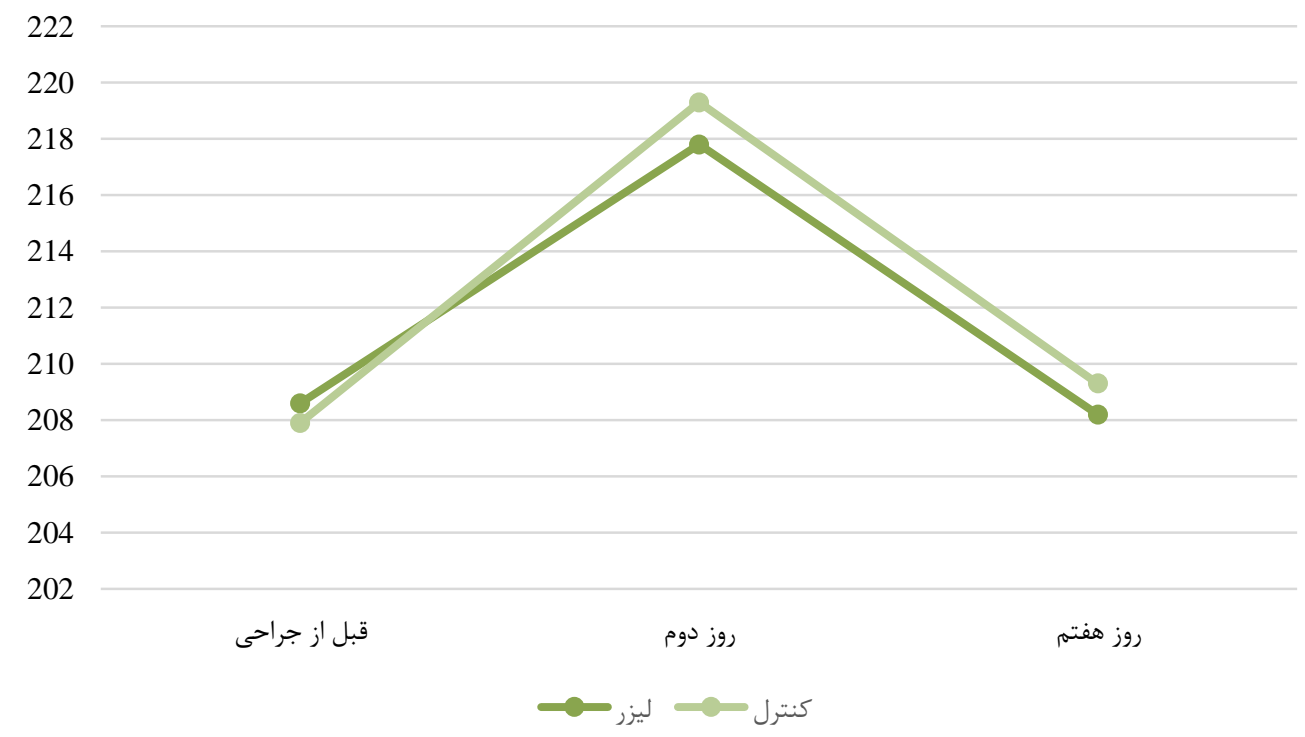

شكل ا: مقايسه ميزان تورم در دو گروه مورد مطالعه در زمانهاى مختلف 
جدول ب: ميانخين حداكثر بازشدن دهان (تريسموس) در زمانهاى مختلف در كروههاى مورد مطالعه

\begin{tabular}{|c|c|c|c|}
\hline سطح معنادارى & ميانكين土|نحراف معيار & 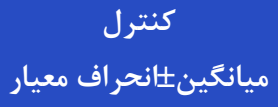 & تريسموس \\
\hline - $|A F|$ & $F / / / \Delta \pm V / \Lambda$ & $r \cdot / / \Delta \pm V / \Delta$ & قبل از جراحى \\
\hline •|rTI & $r \wedge \pm \varphi$ & $r F / V \Delta \pm V / q$ & روز دوم \\
\hline$\cdot|M F|$ & $r q / \wedge \Delta \pm 9 / 9 \vee$ & $r \varphi / \varepsilon \pm \Lambda / \Delta$ & روز هفتم \\
\hline
\end{tabular}

Mann-Whitney آزمون همتم

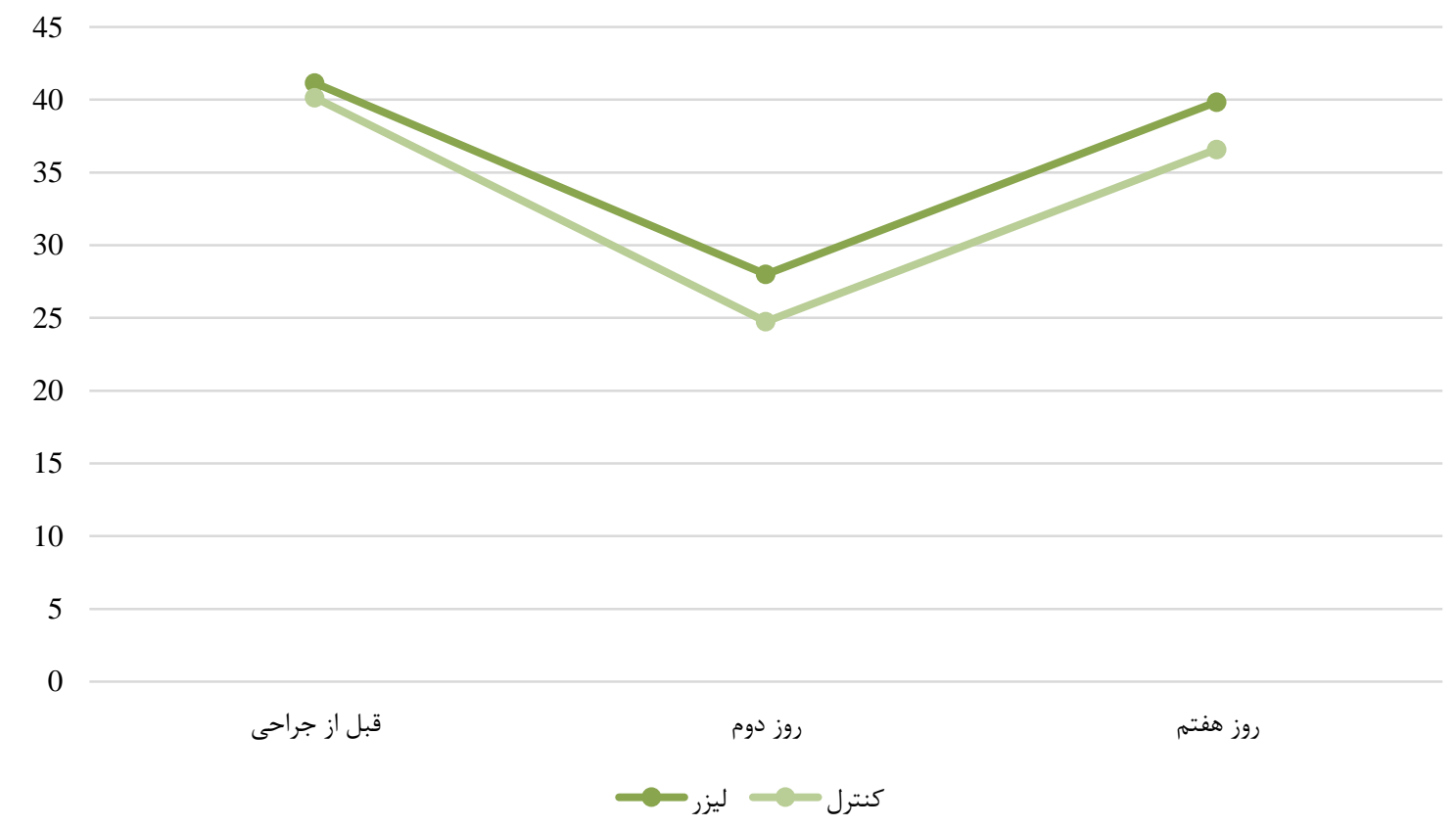

شكل r: مقايسه ميزان حداكثر بازشدن دهان (تريسموس) در دو گروه مورد مطالعه در زمانهاى مختلف

در يى استفاده از ليزر در يك ساعت اول يس از جراحى و نيز

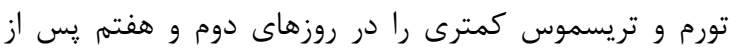

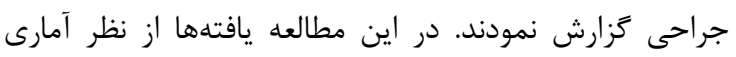

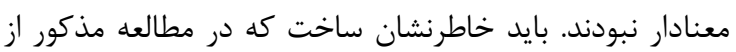

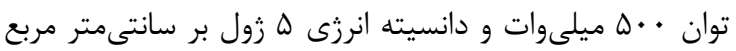

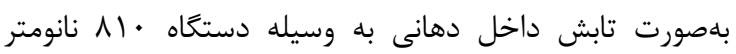

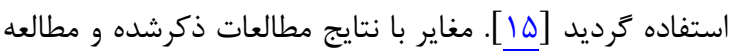

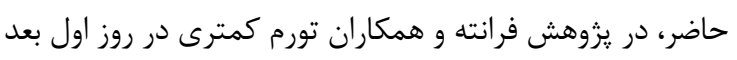

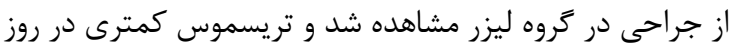

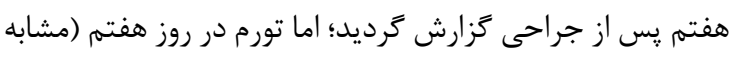

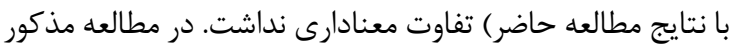

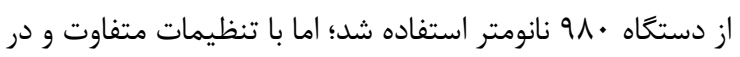

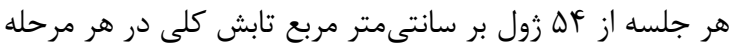

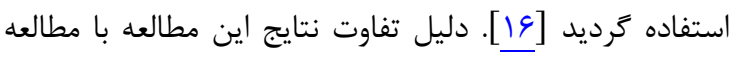

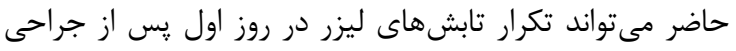

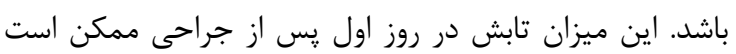

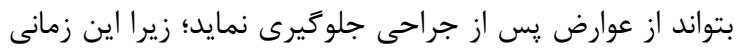
است كه انتظار آغاز تورم را داريم.
براساس نتايج بهدستآمده از اين مطالعه، پيس از تابش

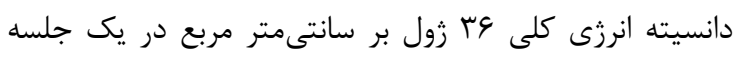

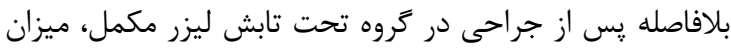

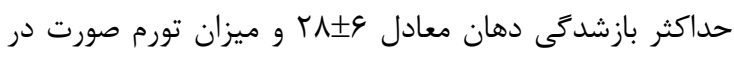

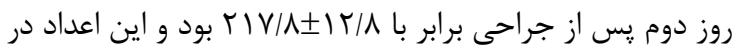

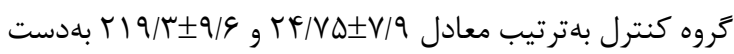

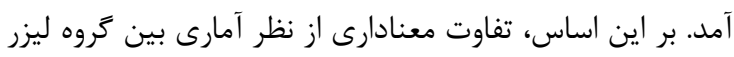

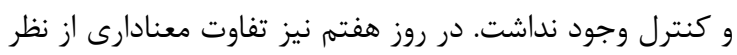

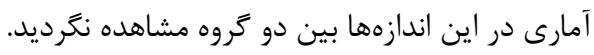
در مطالعهاى كه توسط آلن و همكار ان در مورد اثر تابش ليز ليزر

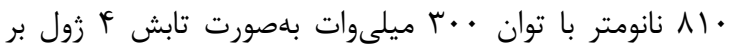

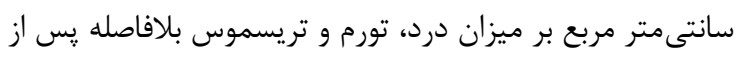

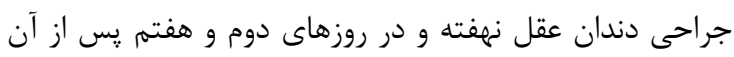

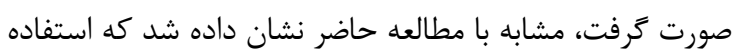

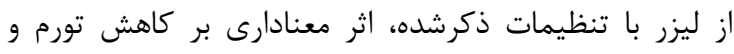

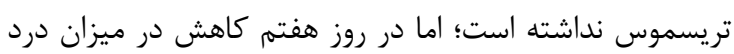

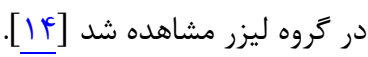
علاومبراين، لويز و همكاران در مطالعه خود درد كمترى رال 
دندان مولرسوم نهفته در فك پايين ندارد.

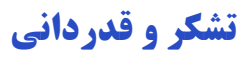

مقاله حاضر بركرفته از پاياننامه دوره دكترى درى حرفهاى

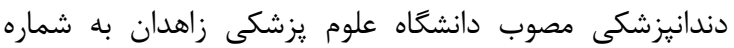

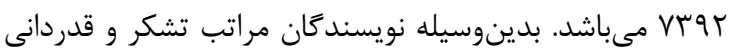
خود را از حمايت و همكارى مركز تحقيقات دهان و دندان اين بندين دانشعاه اعلام مىنمايند.

تضاد منافع نتايج اين مطالعه با منافع نويسندگان در تعارض نمىباشد.

\section{ملا حظات اخلاقى}

مطالعه حاضر داراى تأييديه از كميته اخلاق دانشعاه علوم يزشكى زاهدان بوده (با شماره و در مركز كار آزمايىهاى بالينى كشور ثبت كرديده است ( 20180920041076N1 يزوهشى با راهنمايى و مشاوره نويسنده مسئول مقاله آغاز شد و

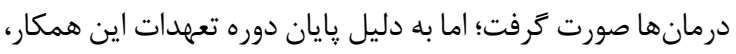
ادامه طرح و دفاع نهايى به نويسنده اول مقاله واكذار كرديد.

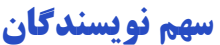

نويسنده اول (يزوهشخر اصلى): تدوين روششناسى، نتايج و

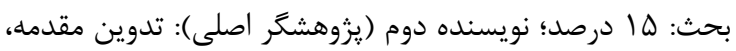
مشاركت در تدوين روششناسى، نتايج، بحث و و ويرايش مقاله:

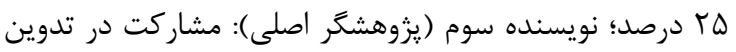

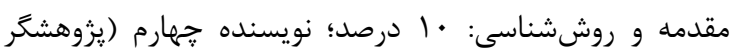

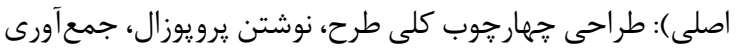

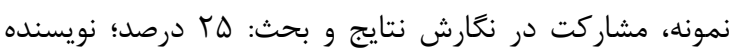

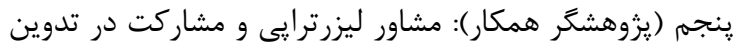

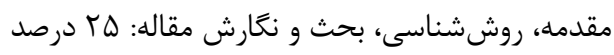

حمايت مالكى هزينه انجام طرح توسط دانشعاه علوم يزشكى زاهدان تأمين

شده است.

\section{REFERENCES}

1. Khiavi RK, Pourallahverdi M, Pourallahverdi A, Khiavi SG, Oskouei SG, Mokhtari H. Pain control following impacted third molar surgery with bupivacaine irrigation of tooth socket: a prospective study. J Dent Res Dental Clin Dent Prospects. 2011;4(4):105-9. PMID: 23346335 DOI: 10.5681/joddd.2010.027

2. Sortino F, Cicciù M. Strategies used to inhibit postoperative swelling following removal of impacted lower third molar. Dent Res J. 2011;8(4):162-71. PMID: 22135686 DOI: 10.4103/1735-3327.86031

3. Amin MM, Laskin DM. Prophylactic use of indomethacin for
از سوى ديگر در مطالعه انجامشده توسط آراس و همكاران

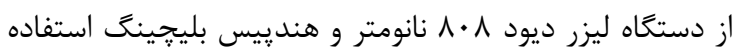

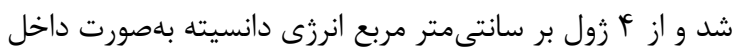

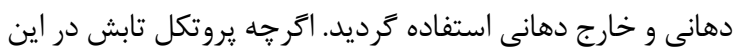

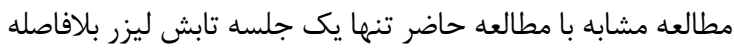

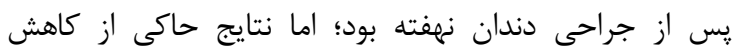

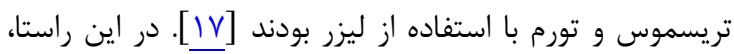

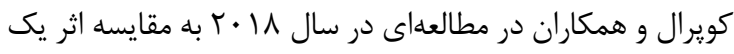

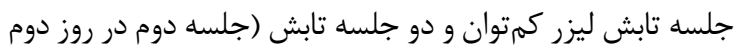

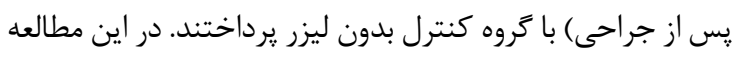

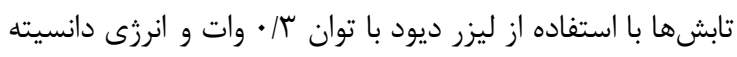

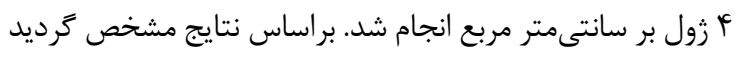

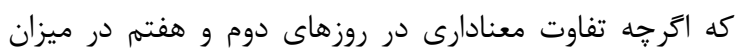

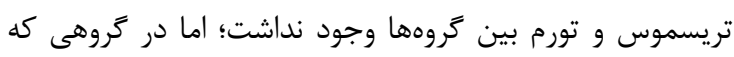

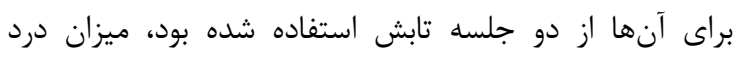

كزارششده در روز هفتم كمتر از گروههاى ديخر بود [111].

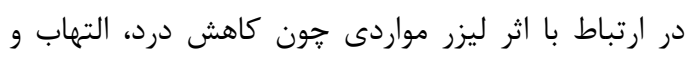

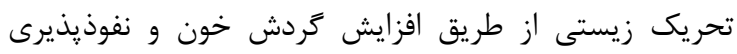

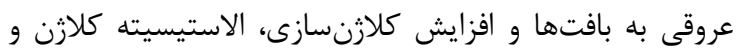

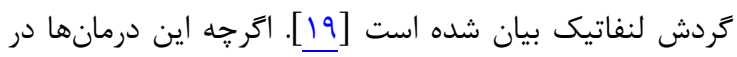

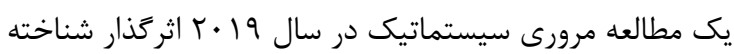

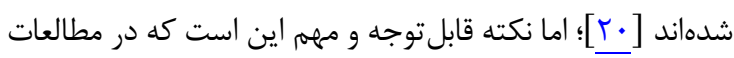

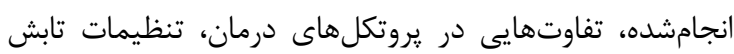

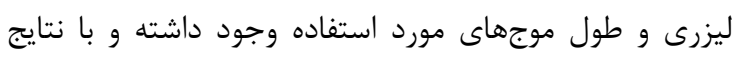
متنوعى در زمينه فوايد كاربرد مكمل اين ليزرها باصصورت كمت موردان يس از جراحى دندان عقل مواجه هستيم. از آنجايى كه اثرات ليزر

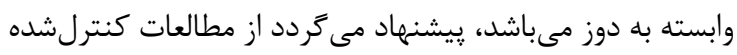

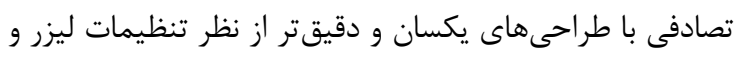

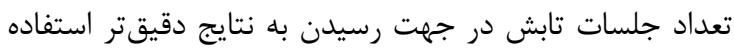

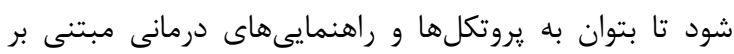
شواهدى در اين زمينه دست يافت. بت برون

\section{نتيجه تيرى}

براساس نتايج مطالعه حاضر مىتوان كفت كه يك جلسه

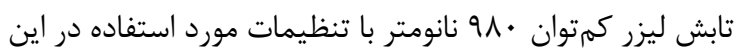

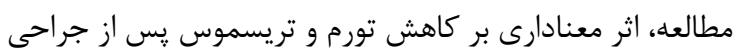

prevention of postsurgical complications after removal of impacted third molars. Oral Surg Oral Med Oral Pathol. 1983;55(5):448-51. PMID: 6575332 DOI: 10.1016/00304220(83)90227-X

4. Ata-Ali Mahmud FJ, Ata-Ali Mahmud F, Peñarrocha Oltra D, Peñarrocha Diago M. Corticosteroids use in controlling pain, swelling and trismus after lower third molar surgery use in controlling pain, swelling and trismus after lower third molar surgery. J Clin Exp Dent. 2011;3(5):e469-75. DOI: 10.4317/jced.i.e469

5. Polat O, Karaman AI, Durmus E. Effects of preoperative 
ibuprofen and naproxen sodium on orthodontic pain. Angle Orthod. 2005;75(5):791-6. PMID: 16279825 DOI: 10.1043/ 0003-3219(2005)75[791:EOPIAN]2.0.CO;2

6. Chavez EM, Taylor GW, Borrell LN, Ship JA. Salivary function and glycemic control in older persons with diabetes. Oral Surg Oral Med Oral Pathol Oral Radiol Endod. 2000;89(3):305-11. PMID: 10710454 DOI: 10.1016/s10792104(00)70093-X

7. Ren C, McGrath C, Yang Y. The effectiveness of low-level diode laser therapy on orthodontic pain management: a systematic review and meta-analysis. Lasers Med Sci. 2015;30(7):1881-93. PMID: 25800534 DOI: $10.1007 / \mathrm{s} 10103-$ 015-1743-4

8. Doeuk C, Hersant B, Bosc R, Lange F, SidAhmed-Mezi M, Bouhassira J, et al. Current indications for low level laser treatment in maxillofacial surgery: a review. $\mathrm{Br} \mathrm{J}$ Oral Maxillofac Surg. 2015;53(4):309-15. PMID: 25740083 DOI: 10.1016/j.bjoms.2015.02.005

9. Carroll JD, Milward MR, Cooper PR, Hadis M, Palin WM. Developments in low level light therapy (LLLT) for dentistry. Dent Mater. 2014;30(5):465-75. PMID: 24656472 DOI: 10.1016/i.dental.2014.02.006

10. Gasperini G, Rodrigues de Siqueira IC, Rezende Costa L. Does low-level laser therapy decrease swelling and pain resulting from orthognathic surgery? Int J Oral Maxillofac Surg. 2014;43(7):868-73. PMID: 24679851 DOI: 10.1016/j. ijom.2014.02.015

11. Fekrazad R, Chiniforush N, Bouraima SA, Valipour M, Aslani M, Zare M, Safari OA. Low level laser therapy in management of complications after intra oral surgeries. $J$ Lasers Med Sci. 2012;3(4):135.

12. Kathuria V, Dhillon JK, Kalra G. Low level laser therapy: a panacea for oral maladies. Laser Ther. 2015;24(3):215-23. PMID: 26557737 DOI: 10.5978/islsm.15-RA-01

13. Amaroli A, Ravera S, Parker S, Panfoli I, Benedicenti A, Benedicenti S. 808-nm laser therapy with a flat-top handpiece photobiomodulates mitochondria activities of Paramecium primaurelia (Protozoa). Lasers Med Sci. 2016;31(4):741-7. PMID: 26984347 DOI: 10.1007/s10103-016-1901-3

14. Alan H, Yolcu Ü, Koparal M, Özgür C, Öztürk SA, Malkoç S. Evaluation of the effects of the low-level laser therapy on swelling, pain, and trismus after removal of impacted lower third molar. Head Face Med. 2016;12(1):25. PMID: 27457369 DOI: 10.1186/s13005-016-0121-1

15. López-Ramírez M, Vílchez-Pérez MÁ, Gargallo-Albiol J, Arnabat-Domínguez J, Gay-Escoda C. Efficacy of low-level laser therapy in the management of pain, facial swelling, and postoperative trismus after a lower third molar extraction. A preliminary study. Lasers Med Sci. 2012;27(3):559-66. PMID: 21617973 DOI: 10.1007/s10103-011-0936-8

16. Ferrante M, Petrini M, Trentini P, Perfetti G, Spoto G. Effect of low-level laser therapy after extraction of impacted lower third molars. Lasers Med Sci. 2013;28(3):845-9. PMID: 22843310 DOI: $10.1007 / \mathrm{s} 10103-012-1174-4$

17. Aras MH, Güngörmüs M. The effect of low-level laser therapy on trismus and facial swelling following surgical extraction of a lower third molar. Photomed Laser Surg. 2009;27(1):21-4. PMID: 19196113 DOI: 10.1089/pho.2008.2258

18. Koparal M, Ozcan Kucuk A, Alan H, Asutay F, Avci M. Effects of low-level laser therapy following surgical extraction of the lower third molar with objective measurement of swelling using a three-dimensional system. Exp Ther Med. 2018;15(4):3820-6. PMID: 29581740 DOI: 10.3892/etm.2018.5921

19. Oliveira Sierra S, Melo Deana A, Mesquita Ferrari RA, Maia Albarello P, Bussadori SK, Santos Fernandes KP. Effect of low-level laser therapy on the post-surgical inflammatory process after third molar removal: study protocol for a double-blind randomized controlled trial. Trials. 2013;14(1):373. PMID: 24195796 DOI: 10.1186/1745-6215$\underline{14-373}$

20. Medeiros AC, Branco GL, de Moura LA. Laser therapy in molars surgery impacted: systematic review. Focus Oral Res. 2019;2(1):59-66. DOI: 10.35169/for.v2i1.44 